\title{
Knowledge and use of unauthorized HIV self-test kits among men who have sex with men in Spain, following approval of an over-the-counter self-test in the U.S: a cross-sectional study
}

Konstantinos Koutentakis ${ }^{1,2}$, María Elena Rosales-Statkus ${ }^{2,3}$, Juan Hoyos ${ }^{3 *}$, Sonia Fernández-Balbuena ${ }^{3,4}$, Mónica Ruiz ${ }^{2,3}$, Cristina Agustí, Luis de la Fuente ${ }^{2,3}$, María José Belza ${ }^{3,4}$ and the Madrid HIV self-testing group

\begin{abstract}
Background: Shortly after the approval of an over-the-counter HIV self-test in the US, we conducted a study to estimate the proportion of men who have sex with men (MSM) in Spain who knew that unauthorized HIV self-tests could be purchased online, and the proportion that had already used these tests, as well as their socio-demographic and behavioural correlates.

Methods: Between September 2012 and February 2013, MSM users of gay dating websites were invited to complete an online questionnaire. We calculated estimates of the knowledge and use of unauthorized HIV self-testing and assessed the associated factors by rare event logit regression models.

Results: Among 8620 participants, $4.2 \%$ (95 \% Cl:3.8-4.6) knew they could buy an unauthorized HIV self-test kit online, and $12.7 \%$ (95\% Cl:12.0-13.4) thought that such a test might exist, although they had never seen one. Only $0.7 \%$ (95 \% Cl:0.5-0.9) had ever self-tested. In the multivariable analysis, knowledge of online availability of self-tests was associated with being a non-Latin American foreigner, having at least two previous HIV tests, intending to test for HIV in the next year, and knowing about U.S. approval of self-testing. Ever-use of HIV self-testing was associated with being over 34 years of age, living outside Spain during the last 12 months, and knowing about U.S. approval of self-testing.
\end{abstract}

Conclusions: Both knowledge and use of unauthorized HIV self-testing among MSM in Spain was very low among HIV negative or untested MSM in Spain. The recent approval in the United Kingdom and France might increase the number of MSM seeking such testing and possibly using unauthorized test kits not meeting quality standards.

Keywords: HIV testing, Preventive behaviour, Men who have sex with men, Self testing

\footnotetext{
*Correspondence: jhoyos@externos.isciii.es

${ }^{3}$ Consortium for Biomedical Research in Epidemiology \& Public Health (CIBERESP), Madrid, Spain

Full list of author information is available at the end of the article
} 


\section{Background}

Rapid test kits to determine the status for HIV and other sexually transmitted infections (STI) have been sold online for years [1]. However, the results of a study conducted to assess the use of internet sites for STI testing and to obtain information about the services offered and validity of the tests were not promising. The internet sites offering HIV tests were found to be difficult to contact, and they were often unwilling to answer consumerspecific questions. Furthermore, the validity of the tests was far from optimal [2].

The approval in 2012 of an over-the-counter HIV selftest for lay people by the United States Food and Drug Administration (FDA) [3, 4] was a crucial event for this testing option in particular, and for HIV testing approaches in general [5]. Its approval was followed by great media coverage, which paved the way for the popularization and future expansion of this testing option, not only in the U.S., but also in Europe.

Thus, in October 2013, the European parliament approved a proposal that left to member states the decision on whether to allow or restrict HIV self-testing. Since then, the United Kingdom (UK) [6] and France [7] have approved and are currently selling HIV self-testing kits (two versions of Chembio's SURE CHECK ${ }^{\odot}$ HIV 1/2 testing device under the brand name "BioSURE HIV self test" in the UK and "Autotest VIH" in France) $[8,9]$. In Spain and the rest of Europe the sale of self-tests remains unauthorized.

Between 2010 and shortly before U.S. approval of HIV self-testing, we performed the first study in Spain to estimate the percentage of potential users who knew that unauthorized HIV self-tests could be purchased online and the percentage that had already used them among people receiving HIV rapid testing at a street-based program [10]. Given its study population, that study was unable to collect information on people who had never been tested (those who responded not having tested before were de facto receiving their first one that day).

Immediately after the approval of HIV self-testing in the U.S. and the mass media attention that followed, we initiated a new study focusing on men who have sex with men (MSM) - the group most affected by HIV in our country - to capture information on individuals with no previous testing experience. MSM non-testers are one of the population groups that could benefit the most from approval of HIV self-testing, given their high vulnerability and reluctance to attend existing sites $[11,12]$.

In the context of the media exposure that followed U.S. approval of HIV self-testing, we calculated the proportion of MSM in Spain who knew that unauthorized HIV self-tests could be purchased online, as well as the proportion who had already used such tests, and estimated the socio-demographic and behavioural correlates associated with both knowledge and use.

\section{Methods \\ Study procedures and participants}

The study was conducted online from September 2012 to February 2013 via dating and chatting websites oriented to gay men, as well as via organizations of lesbian, gay, transsexual and bisexual (LGTB) individuals and non-governmental organization (NGO) sites. On the websites' front page display, links or banner advertisements invited users to take part in the survey. Some associations also emailed their members inviting them to participate. A total of $68 \%$ of the respondents were recruited from three participating internet sites.

Those who chose to access the survey website were informed of the rationale and purposes of the study. Participants were also informed of the estimated time to complete the questionnaire (15 min). No Internet Protocols or cookies were collected. The questions were designed to elicit no identifying information; for example, participants were asked to report their age in years rather than their date of birth. Likewise, we did not include questions on the city or town of residence; instead, we asked only about the approximate number of inhabitants. As informed consent was not possible, candidates were asked to click on an "I agree to participate button" before having access to the questionnaire. Participants were able to go back to previously answered questions, in order to check and/or change them, before final submission. The eligibility criteria were: a) age $\geq 18$ years, b) being male at birth and ever having had sex with a male and c) currently residing in Spain and accessing the survey page while in the country. The study was approved by the Carlos III health institute ethical committee (CEI PI 70_2015).

\section{Data collection instrument}

We developed an online self-administered questionnaire which covered demographic characteristics, sexual orientation and the involvement with the gay scene. Involvement was assessed with a 4 item question: "I am a member of a LGTB Community Based Organization" "I attend gay venues with my friends on a frequent basis" "I only attend gay venues to hook up with men" "I have virtually never attended a gay venue". Participants answered "yes" or "no" to each one of them. Those who answered "yes" to the first item were labeled as "Member of a gay CBO" regardless of the other items. Those who answered "no" to the first item but answered "yes" to the 2nd or 3rd item, were labeled as "Not member of a gay CBO-Frequents the gay scene". Finally those who answered "yes" to the 4th item were labelled as "No involvement with gay scene". 
Questionnaire also assessed the number of sexual relationships in the last 12 months, risk behaviours, HIV/ STDs status, and HIV testing history. Those participants who self-reported being HIV positive were asked about the process leading to their positive diagnosis, possible missed opportunities for earlier diagnosis, and the process of linkage to care. For those who had never been tested or who self-reported being HIV negative - i.e., the future potential users of self-testing - we inquired about self-testing. First, their knowledge of the possibility of purchasing an unauthorized HIV self-test online was measured by a question with three response options: "Yes, I knew about it", "I thought it could exist, although I had never seen it" and "I had no idea about it". Those who knew about self-testing were asked if they had ever self-tested. They were asked to choose one of the three following responses: "Never", "Yes, once", and "Yes, more than once". We also included a specific section for those who reported having ever performed a self-test. It included questions on the exact number of self-tests conducted and on the difficulty to follow the instructions of each of the steps of the testing process, which was assessed with a five-item scale question: $1=$ Very easy, $2=$ Quite easy, $3=$ Somewhat difficult, $4=$ Quite difficult, $5=$ Very difficult. The dataset supporting the conclusions of this article is included within the article and its Additional file 1.

\section{Data analysis}

In total, 13,150 users submitted a completed questionnaire, of whom 9489 self-identified themselves as HIV negative or had an unknown status and therefore were given the opportunity to answer the questions related to self-testing. We excluded 55 participants who stated they were under 18 years old or had some inconsistent responses regarding their HIV status, and 814 subjects were also excluded for not answering the questions related to HIV self-testing. The final sample used for the analysis was 8620 participants.

We calculated proportions for the qualitative variables and, to summarize the quantitative variables, we grouped them into categories and calculated the relative frequencies. 5-point scale variables were treated as categorical. We performed a descriptive analysis of the categorical characteristics stratified by HIV testing history (ever tested/never tested), and we calculated the chisquare statistic to test for dependency between them. Some categories of the independent variables were merged to allow comparisons in statistical testing. The two main outcome variables were re-coded into binary ones in order to build logit regression models. The first dependent variable, which examined the proportion of MSM that knew about HIV self-testing, was grouped as "Yes I knew about it" and "I thought it could exist, although I had never seen it/I had no idea about it". Similarly, the second dependent variable, which measured the proportion of HIV self-testers, was re-coded as "Ever self-tested, once or more times" and "Never self- tested".

Estimations of factors associated with the knowledge and ever-use of unauthorized HIV self-testing were examined by calculating odds ratios (OR) and the corresponding $95 \%$ confidence intervals $(\mathrm{CI})$ through logistic regression for rare events data $[13,14]$. All the statistically significant factors at $p \leq 0.1$ in the single variable analysis were entered in a multivariable rare event logit regression model that was built for each outcome. All these analyses were performed using STATA v12 software using the relogit command.

\section{Results}

\section{Demographic characteristics}

A detailed descriptive analysis of the characteristics of the sample stratified by HIV testing history is presented in Table 1, which shows statically significant differences in the distribution of several variables between those who have never been tested $(28.6 \%)$ and those with testing experience (71.4\%).

Among all the participants, $56.6 \%$ were under 35 years old, $54.9 \%$ had a university degree, only $13.2 \%$ was born abroad, and $41.3 \%$ had no involvement in the gay scene. Some $60.2 \%$ reported unprotected anal intercourse during the last 12 months, $7.0 \%$ had ever paid for sex, and an additional $4.5 \%$ reported having ever been paid for sex. The reported prevalence of injected drug use was very low (1.2\%). Overall, $58.4 \%$ had the intention to be tested for HIV in the next year, although this proportion was lower among those who had never been tested $(28.1 \%) ; 6.1 \%$ knew about the availability of the overthe-counter self-test in the U.S. Among those who had ever been tested, $57.4 \%$ had been tested at least three times, and $44.7 \%$ had done so within the last year.

\section{Knowledge of online sale of unauthorized rapid HIV home kits for self-testing}

Overall, only 360 MSM (4.2 \%; 95 \% CI: 3.8-4.6) knew that they could buy unauthorized test kits online to perform self-testing, and an additional $12.7 \%$ (95 \% CI: 12.0-13.4) thought that such kits might exist, although they had never seen them. Sixty four (18.3\%) out of 350 MSM knew a person who had performed an HIV self-test.

The channels of information through which MSM seem to have come across HIV self-testing were: internet commercials (53.1\%), online videos-trailers talking about self-testing (24.5\%), friends (18.9\%), advertisements posted in gay dating sites (16.7\%), announcements in gay associations (12.2\%), and via their sexual partners $(4.7 \%)$. 
Table 1 Sociodemographics, risk behaviors and HIV testing intentions by HIV testing history of MSM websites' users

\begin{tabular}{|c|c|c|c|c|c|c|c|}
\hline & \multicolumn{2}{|c|}{ Never tested $n=2464(28.6 \%)$} & \multicolumn{2}{|c|}{ Ever tested $n=6156(71.4 \%)$} & \multicolumn{2}{|c|}{ Total $n=8620$} & \multirow[b]{2}{*}{$P$-value } \\
\hline & $\bar{n}$ & $\%$ & $\bar{n}$ & $\%$ & 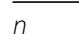 & $\%$ & \\
\hline Age & & & & & & & $<0.001$ \\
\hline $18-24$ & 852 & 34.6 & 815 & 13.3 & 1667 & 19.4 & \\
\hline $25-34$ & 836 & 34.0 & 2366 & 38.5 & 3202 & 37.2 & \\
\hline $35-44$ & 446 & 18.1 & 1845 & 30.0 & 2291 & 26.6 & \\
\hline$\geq 45$ & 327 & 13.3 & 1121 & 18.2 & 1448 & 16.8 & $<0.001$ \\
\hline \multicolumn{8}{|l|}{ Education } \\
\hline None/Primary/Secondary & 405 & 16.5 & 773 & 12.6 & 1178 & 13.7 & \\
\hline Higher secondary & 890 & 36.2 & 1805 & 29.4 & 2695 & 31.4 & \\
\hline University & 1162 & 47.3 & 3561 & 58.0 & 4723 & 54.9 & \\
\hline Place of birth & & & & & & & $<0.001$ \\
\hline Spain & 2271 & 92.2 & 5217 & 84.7 & 7488 & 86.9 & \\
\hline Latin-America & 117 & 4.7 & 544 & 8.8 & 661 & 7.7 & \\
\hline Other country & 76 & 3.1 & 395 & 6.4 & 471 & 5.5 & \\
\hline Place of residence ${ }^{b}$ & & & & & & & 0.073 \\
\hline Spain & 2310 & 96.0 & 5698 & 95.0 & 8008 & 95.2 & \\
\hline Latin-America & 23 & 1.0 & 91 & 1.5 & 114 & 1.4 & \\
\hline Other country & 74 & 3.1 & 212 & 3.5 & 286 & 3.4 & \\
\hline City residence (inhabitants) ${ }^{b}$ & & & & & & & $<0.001$ \\
\hline$<100,000$ & 1014 & 42.2 & 1875 & 31.3 & 2889 & 34.4 & \\
\hline $100,000-500,000$ & 616 & 25.6 & 1428 & 23.8 & 2044 & 24.4 & \\
\hline$>500,000$ & 773 & 32.2 & 2686 & 44.8 & 3459 & 41.2 & \\
\hline Involvement with the gay scene & & & & & & & $<0.001$ \\
\hline Member of a gay $\mathrm{CBO}^{c}$ & 59 & 2.5 & 391 & 6.6 & 450 & 5.4 & \\
\hline Not member of a gay CBO-Frequents the gay scene & 875 & 37.3 & 3530 & 59.6 & 4405 & 53.3 & \\
\hline Not related to gay scene & 1410 & 60.2 & 2006 & 33.8 & 3416 & 41.3 & \\
\hline No. of male sexual partners ${ }^{b}$ & & & & & & & $<0.001$ \\
\hline 0 & 129 & 5.3 & 121 & 2.0 & 250 & 2.9 & \\
\hline $1-4$ & 1216 & 49.9 & 2109 & 34.7 & 3325 & 39.1 & \\
\hline $5-9$ & 540 & 22.2 & 1316 & 21.7 & 1856 & 21.8 & \\
\hline $10-19$ & 341 & 14.0 & 1315 & 21.7 & 1656 & 19.5 & \\
\hline$\geq 20$ & 210 & 8.6 & 1211 & 19.9 & 1421 & 16.7 & \\
\hline Anal intercourse and condom use $\mathrm{e}^{\mathrm{b}}$ & & & & & & & $<0.001$ \\
\hline No anal intercourse & 129 & 5.3 & 121 & 2.0 & 250 & 3.0 & \\
\hline Had but all were protected & 937 & 38.7 & 2185 & 36.2 & 3122 & 36.9 & \\
\hline Had unprotected anal sex & 1357 & 56.0 & 3734 & 61.8 & 5091 & 60.2 & \\
\hline Ever paid for sex & 176 & 7.2 & 419 & 6.9 & 595 & 7.0 & 0.572 \\
\hline Ever been paid for sex & 99 & 4.1 & 286 & 4.7 & 385 & 4.5 & 0.201 \\
\hline Injected drug use (Ever) & 27 & 1.1 & 72 & 1.2 & 99 & 1.2 & 0.763 \\
\hline \multicolumn{8}{|l|}{ No. of previous HIV tests } \\
\hline 1 & & & 1302 & 21.2 & & & \\
\hline 2 & & & 1320 & 21.4 & & & \\
\hline$>2$ & & & 3534 & 57.4 & & & \\
\hline
\end{tabular}


Table 1 Sociodemographics, risk behaviors and HIV testing intentions by HIV testing history of MSM websites' users (Continued)

\begin{tabular}{|c|c|c|c|c|c|c|c|}
\hline \multicolumn{8}{|l|}{ Time since last HIV test (years) } \\
\hline$<1$ & & & 2747 & 44.7 & & & \\
\hline $1-3$ & & & 2527 & 41.1 & & & \\
\hline $4-5$ & & & 451 & 7.3 & & & \\
\hline $6-10$ & & & 307 & 5.0 & & & \\
\hline$>10$ & & & 116 & 1.9 & & & \\
\hline HIV testing intention in the next year & & & & & & & $<0.001$ \\
\hline Certainly yes & 258 & 10.5 & 2793 & 45.4 & 3051 & 35.4 & \\
\hline Probably yes & 434 & 17.6 & 1544 & 25.1 & 1978 & 23.0 & \\
\hline Not sure & 984 & 40.0 & 1125 & 18.3 & 2109 & 24.5 & \\
\hline Probably no & 576 & 23.4 & 551 & 9.0 & 1127 & 13.1 & \\
\hline Certainly no & 209 & 8.5 & 137 & 2.2 & 346 & 4.0 & \\
\hline Knows about the availability of self-testing in the USA & & & & & & & $<0.001$ \\
\hline I had no idea about it & 2076 & 84.4 & 4697 & 76.6 & 6773 & 78.8 & \\
\hline I thought it could exist, although I had never seen it & 284 & 11.5 & 1014 & 16.5 & 1298 & 15.1 & \\
\hline Yes I knew about it & 100 & 4.1 & 424 & 6.9 & 524 & 6.1 & \\
\hline
\end{tabular}

a Level of significance was examined by chi-square test; ${ }^{\mathrm{b}}$ Last 12 months; ${ }^{\mathrm{c}} \mathrm{CBO}$ : Community based organization

In the univariable logistic regression for rare events analysis (Table 2), the knowledge that unauthorized self-tests for HIV kits can be purchased online was significantly and positively associated with being born and residing the last year in a foreign non-Latin American country (OR: 1.9; 95 \% CI: 1.3-2.8 and OR: 2.0; 95 \% CI: 1.3-3.1, respectively), living in a city with more than 500,000 inhabitants (OR: 1.3; 95 \% CI: 1.1-1.6), having at least two previous HIV tests (OR: 1.9; $95 \%$ CI: 1.5-2.3), having the intention of being tested in the upcoming year (OR: 1.9; $95 \%$ CI: 1.5-2.4), and knowing about the US approval of HIV selftesting (OR: 5.2; 95 \% CI: 4.2-6.5). Knowledge of possible online purchase of these kits was negatively associated with not being a member of a gay organization (OR: 0.5; 95 \% CI: $0.4-0.8)$ or having no involvement with the gay scene (OR: 0.5; 95 \% CI: 0.4-0.8).

In the multivariable analysis, this knowledge remained significantly associated with having resided in a foreign non-Latin American country in the last year (OR: 1.9; $95 \%$ CI: 1.1-3.1), having at least two previous HIV tests (OR: 1.4; $95 \%$ CI: 1.0-1.8), the intention of being tested in the upcoming year (OR: 1.5; $95 \%$ CI: 1.2-2.0) and being aware that HIV self-testing had become available in the U.S. (OR: 4.9; 95 \% CI: 3.9-6.2).

\section{Self-testing for HIV with an unauthorized rapid kit purchased on the internet}

A total of 61 participants (0.7\%; $95 \%$ CI: 0.54-0.91) had ordered from the internet and used the rapid selftest at least once $(16.9 \%$ of the 360 MSM who knew about the availability of online unauthorized self-testing kits). Eighty-six point six percent of the HIV kits purchased were blood-based, whereas the percentage of participants that reported having purchased either a saliva or a urine based kit was of $6.7 \%$ in both cases.. Except for one, all self-testers reported that the instructions on how to obtain the sample and perform the self-test were "very easy" (62.7\%) or "quite easy" (35.6\%). All selftesters interpreted a negative test result and all said that instructions explaining how to interpret the self-test were "very easy" (68.4\%) or "quite easy" (31.6 \%). Fortyfive men performed the test completely alone; eleven were accompanied by their sexual partner and three by a friend. Sixteen of them followed the self-test with a conventional test, which was found to be negative. Eleven of them took the conventional test within the first month and three at a later period.

The unadjusted analysis (Table 3) showed that selftesters were more likely to be over 34 years old (OR: 2.0; $95 \%$ CI: 1.2-3.4), hold a university degree (OR: 1.9; $95 \%$ CI: 1.1-3.4), reside outside Spain in the last 12 months (OR: 3.4; 95 \% CI: 1.6-7.3), have at least two previous HIV tests (OR: 2.3; $95 \%$ CI: 1.3-4.2), have the intention to be tested in the upcoming year (OR: 2.6; 95 \% CI: 1.4-4.8), and to know that HIV self-testing had become available in U.S. (OR: 5.1; 95 \% CI: 3.0-8.4).

In the adjusted analysis, being an HIV self-tester was significantly associated with being over 34 years of age (OR: 1.7; 95 \% CI: 1.0-2.9), having lived in a country other than Spain the last 12 months (OR: 3.1; 95 \% CI: 1.5-6.8), having the intention to test for HIV in the upcoming year (OR: 1.8; $95 \% \mathrm{CI}: 1.0-3.5$ ) and knowing 
Table 2 Knowledge of unauthorized HIV self-testing and associated factors in MSM websites' users. Crude and adjusted analysis

\begin{tabular}{|c|c|c|c|c|c|c|}
\hline & Number & Percent & $\begin{array}{l}\text { Crude odds } \\
\text { ratio }\end{array}$ & $\begin{array}{l}95 \% \text { confidence } \\
\text { interval }\end{array}$ & $\begin{array}{l}\text { Adjusted odds } \\
\text { ratio }\end{array}$ & $\begin{array}{l}95 \% \text { confidence } \\
\text { interval }\end{array}$ \\
\hline \multicolumn{7}{|l|}{ Age } \\
\hline$<35$ & 187 & 3.8 & Ref. & & Ref. & \\
\hline$\geq 35$ & 171 & 4.6 & 1.2 & $0.9-1.5$ & 1.0 & $0.8-1.3$ \\
\hline \multicolumn{7}{|l|}{ Education } \\
\hline$<$ University & 149 & 3.8 & Ref. & & & \\
\hline University & 210 & 4.4 & 1.2 & $0.9-1.4$ & & \\
\hline \multicolumn{7}{|l|}{ Place of birth } \\
\hline Spain & 296 & 4.0 & Ref. & & Ref. & \\
\hline Latin-America & 30 & 4.5 & 1.2 & $0.8-1.7$ & 1.1 & $0.8-1.7$ \\
\hline Other country & 34 & 7.2 & 1.9 & $1.3-2.8$ & 1.4 & $0.9-2.1$ \\
\hline \multicolumn{7}{|l|}{ Place of residence ${ }^{b}$} \\
\hline Spain & 315 & 3.9 & Ref. & & Ref. & \\
\hline Latin-America & 2 & 1.8 & 0.6 & $0.1-2.3$ & 0.4 & $0.1-1.4$ \\
\hline Other country & 21 & 7.3 & 2.0 & $1.3-3.1$ & 1.9 & $1.1-3.1$ \\
\hline \multicolumn{7}{|l|}{ City of residence (inhabitants) ${ }^{\mathrm{b}}$} \\
\hline$\leq 500,000$ & 176 & 3.6 & Ref. & & Ref. & \\
\hline$>500,000$ & 161 & 4.7 & 1.3 & $1.1-1.6$ & 1.1 & $0.9-1.4$ \\
\hline \multicolumn{7}{|l|}{ Involvement with the gay scene } \\
\hline Member of a gay $\mathrm{CBO}^{c}$ & 32 & 7.1 & Ref. & & Ref. & \\
\hline Not member of a gay CBO-Frequents the gay scene & 172 & 3.9 & 0.5 & $0.4-0.8$ & 0.7 & $0.5-1.1$ \\
\hline Not related to gay scene & 133 & 3.9 & 0.5 & $0.4-0.8$ & 0.9 & $0.6-1.4$ \\
\hline \multicolumn{7}{|l|}{ No. of male sexual partners ${ }^{b}$} \\
\hline $0-1$ & 50 & 3.6 & Ref. & & & \\
\hline $2-4$ & 85 & 3.9 & 1.1 & $0.8-1.6$ & & \\
\hline $5-9$ & 71 & 3.8 & 1.1 & $0.7-1.6$ & & \\
\hline$>10$ & 138 & 4.5 & 1.3 & $0.9-1.8$ & & \\
\hline \multicolumn{7}{|l|}{ Anal intercourse and condom use $\mathrm{e}^{\mathrm{b}}$} \\
\hline No anal intercourse & 5 & 2.0 & Ref. & & & \\
\hline Had anal intercourse (with or without condom use) & 335 & 4.1 & 1.9 & $0.8-4.6$ & & \\
\hline \multicolumn{7}{|l|}{ Ever paid for sex } \\
\hline No & 315 & 4.0 & Ref. & & & \\
\hline Yes & 31 & 5.2 & 1.4 & $0.9-2.0$ & & \\
\hline \multicolumn{7}{|l|}{ Ever been paid for sex } \\
\hline No & 326 & 4.0 & Ref. & & & \\
\hline Yes & 21 & 5.5 & 1.4 & $0.9-2.2$ & & \\
\hline \multicolumn{7}{|l|}{ Injected drug use } \\
\hline Ever & 3 & 3.0 & Ref. & & & \\
\hline Never & 338 & 4.1 & 1.6 & $0.4-3.7$ & & \\
\hline \multicolumn{7}{|l|}{ No. of previous HIV tests } \\
\hline $0-1$ & 108 & 2.9 & Ref. & & Ref. & \\
\hline$\geq 2$ & 252 & 5.2 & 1.9 & $1.5-2.3$ & 1.4 & $1.0-1.8$ \\
\hline
\end{tabular}


Table 2 Knowledge of unauthorized HIV self-testing and associated factors in MSM websites' users. Crude and adjusted analysis (Continued)

\begin{tabular}{|c|c|c|c|c|c|c|}
\hline \multicolumn{7}{|l|}{ HIV testing intention in the next year } \\
\hline Certainly no/Probably no/Not sure & 99 & 2.8 & Ref. & & Ref. & \\
\hline Certainly yes/Probably yes & 259 & 5.2 & 1.9 & $1.5-2.4$ & 1.5 & $1.2-2.0$ \\
\hline \multicolumn{7}{|l|}{ Knows about the availability of self-testing in the USA } \\
\hline $\begin{array}{l}\text { I thought it could exist, although I had never seen } \\
\text { it/l had no idea about it }\end{array}$ & 158 & 2.3 & Ref. & & Ref. & \\
\hline Yes I knew about it & 202 & 11.1 & 5.2 & $4.2-6.5$ & 4.9 & $3.9-6.2$ \\
\hline
\end{tabular}

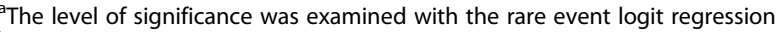

bLast 12 months

${ }^{\mathrm{C}} \mathrm{CBO}$ : Community based organization

about the approval of self-testing in the U.S. (OR: 4.4; 95 \% CI: 2.6-7.4).

\section{Discussion}

This study shows that less than $5 \%$ of Spanish MSM were aware of the availability on the internet of unauthorized and unreliable self-testing kits for HIV, and less than $1 \%$ had ever used these kits shortly after having been exposed to mass media information related with the approval of over-the-counter HIV self-testing in the U.S. Knowledge of online availability was associated with residing in a foreign non-Latin American country, having at least two previous HIV tests, intending to be tested for HIV in the next year, and knowing about US approval of self-testing. Ever-use of an HIV self-test was associated with being over 34 years of age, living outside Spain the last 12 months, and knowing about the U.S. approval of self-testing.

The proportion of participants that knew about the availability of unauthorized HIV self-testing online $(4.2 \%)$ and the proportion of self-testers $(0.7 \%)$ in this study were lower than those observed among Spanish MSM in a previous study carried out between 2010 and 2012 (7.4 and $0.9 \%$ respectively) [10], which was completed 3 months before the U.S. approval of self-testing. Part of this difference could be explained by the fact that all the participants in the previous Spanish study were MSM who sought an HIV test, whereas three out of ten participants in the present study had never been tested. The number of HIV tests was associated with knowledge of online availability of HIV testing in both studies, thus, the fact that almost one-third of the recruited sample had no HIV testing experience could partially explain the slightly lower knowledge found in this study. If we re-run our analysis excluding those participants who reported no previous testing experience, the prevalence of knowledge and use both increase slightly $(4.8 \%$ and $1.0 \%$ respectively). Thus, the prevalence of knowledge still remains lower than that of the Spanish study where all men had previous HIV testing history [10] whereas the prevalence of participants who reported ever having bought an HIV self-testing kit is slightly higher. However, it is also true that participants in the present study were recruited online, and it is likely that they are more familiar with the internet.

Knowledge and use of HIV self-testing in the two Spanish studies were substantially lower than in a French study carried out among MSM in 2009 using a web-based recruitment approach very similar to the one used in the present study [15]. In our study, knowledge of the existence of unauthorized kits was associated with living in a non-Latin American country, whereas their use was found to be associated with having lived outside of Spain during the last 12 months. Thus, even though HIV self-testing has proven to be an acceptable and convenient HIV testing method in the U.S. and other high income countries [16], we can conclude that there is no evidence that the information related with the approval of over-the-counter self-test kits in the U.S. has increased the awareness of the existence of an online market of self-test kits in MSM in Spain. Finally, we should bear in mind some limitations arising from the design and procedures of the study: an online recruitment of a convenience sample. Although this procedure allowed us to reach a large sample of electronically-connected key populations - with participation from all of Spain's 17 autonomous regions - generalization to the total Spanish MSM population should be made with caution. The percentage of non-response to questions on self-testing (8.6\%) may have introduced a response bias. The non-respondents were significantly different in some characteristics from those who did answer questions related to self-testing: they tended to be older, have lower educational level, and a slightly higher presence of Latin Americans, and also of participants who were not thinking of getting tested in the next year and who had not heard of the availability of selftesting in the U.S.

As no identification data was collected, some individuals could have submitted more than one questionnaire. To control this possibility, participants were shown a note before being directed to the first page of the questionnaire 
Table 3 Use of unauthorized HIV self-testing kits and associated factors in MSM websites' users. Crude and adjusted analysis

\begin{tabular}{|c|c|c|c|c|c|c|}
\hline & Number & Percent & $\begin{array}{l}\text { Crude odds } \\
\text { ratio }\end{array}$ & $\begin{array}{l}95 \% \text { confidence } \\
\text { interval }\end{array}$ & $\begin{array}{l}\text { Adjusted odds } \\
\text { ratio }\end{array}$ & $\begin{array}{l}95 \% \text { confidence } \\
\text { interval }\end{array}$ \\
\hline \multicolumn{7}{|l|}{ Age } \\
\hline$<35$ & 24 & 0.5 & Ref. & & Ref. & \\
\hline$\geq 35$ & 37 & 1.0 & 2.0 & $1.2-3.4$ & 1.7 & $1.0-2.9$ \\
\hline \multicolumn{7}{|l|}{ Education } \\
\hline$<$ University & 18 & 0.5 & Ref. & & Ref. & \\
\hline University & 43 & 0.9 & 1.9 & $1.1-3.4$ & 1.5 & $0.8-2.6$ \\
\hline \multicolumn{7}{|l|}{ Place of birth } \\
\hline Spain & 51 & 0.7 & Ref. & & & \\
\hline Latin-America & 4 & 0.6 & 1.0 & $0.4-2.8$ & & \\
\hline Other country & 6 & 1.3 & 2.0 & $0.9-4.7$ & & \\
\hline \multicolumn{7}{|l|}{ Place of residence ${ }^{b}$} \\
\hline Spain & 49 & 0.6 & Ref. & & Ref. & \\
\hline Other country & 8 & 2.0 & 3.4 & $1.6-7.3$ & 3.1 & $1.5-6.8$ \\
\hline \multicolumn{7}{|l|}{ City of residence (inhabitants) } \\
\hline$>500,000$ & 22 & 0.6 & Ref. & & & \\
\hline $100,000-500,000$ & 12 & 0.6 & 0.9 & $0.5-1.9$ & & \\
\hline$<100,000$ & 22 & 0.8 & 1.2 & $0.7-2.2$ & & \\
\hline \multicolumn{7}{|l|}{ Involvement with the gay scene } \\
\hline Member of a gay $\mathrm{CBO}^{c}$ & 1 & 0.2 & Ref. & & & \\
\hline Not member of a gay CBO-Frequents the gay scene & 33 & 0.8 & 2.1 & $0.3-15.3$ & & \\
\hline Not related to gay scene & 23 & 0.7 & 1.9 & $0.3-14.0$ & & \\
\hline \multicolumn{7}{|l|}{ No. of male sexual partners ${ }^{b}$} \\
\hline $0-1$ & 8 & 0.6 & Ref. & & & \\
\hline $2-4$ & 14 & 0.6 & 1.1 & $0.5-2.6$ & & \\
\hline $5-9$ & 12 & 0.7 & 1.1 & $0.5-2.7$ & & \\
\hline$>10$ & 24 & 0.8 & 1.3 & $0.6-2.9$ & & \\
\hline \multicolumn{7}{|l|}{ Anal intercourse and condom use $\mathrm{e}^{\mathrm{b}}$} \\
\hline No anal intercourse & 1 & 0.4 & Ref. & & & \\
\hline Had anal intercourse (with or without condom use) & 56 & 0.7 & 1.1 & $0.2-7.6$ & & \\
\hline \multicolumn{7}{|l|}{ Ever paid for sex } \\
\hline Yes & 56 & 0.7 & Ref. & & & \\
\hline No & 3 & 0.5 & 1.2 & $0.4-3.8$ & & \\
\hline \multicolumn{7}{|l|}{ Ever been paid for sex } \\
\hline No & 3 & 0.8 & Ref. & & & \\
\hline Yes & 56 & 0.7 & 1.3 & $0.4-4.3$ & & \\
\hline \multicolumn{7}{|l|}{ No. of previous HIV tests } \\
\hline $0-1$ & 15 & 0.4 & Ref. & & Ref. & \\
\hline$\geq 2$ & 46 & 0.9 & 2.3 & $1.3-4.2$ & 1.3 & $0.7-2.5$ \\
\hline \multicolumn{7}{|l|}{ HIV testing intention in the next year } \\
\hline Certainly no/Probably no/Not sure & 13 & 0.4 & Ref. & & Ref. & \\
\hline Certainly yes/Probably yes & 48 & 1.0 & 2.6 & $1.4-4.8$ & 1.8 & $1.0-3.5$ \\
\hline
\end{tabular}


Table 3 Use of unauthorized HIV self-testing kits and associated factors in MSM websites' users. Crude and adjusted analysis (Continued)

\author{
Knows about the availability of self-testing in the USA \\ I thought it could exist, although I had never seen \\ it/l had no idea about it \\ Yes I knew about it \\ ${ }^{a}$ The level of significance was examined with the rare event logit regression \\ bast 12 months \\ ${ }^{\mathrm{C}} \mathrm{CBO}$ : Community based organization
}

asking them not to fill it out if they had already participated in the study. We also checked for duplicate entries during quality control analysis as a way of reducing the effect of this limitation. Because the questionnaire was selfcompleted rather than administered by an interviewer, it was easier to stop before answering all the questions, but this also allowed respondents to answer in a more relaxed environment less prone to social desirability bias. Finally, despite having employed a special methodology to analyse the correlates of the main outcomes, the variability caused by the low number of events could have limited the robustness of the estimates.

\section{Conclusions}

In conclusion, knowledge of HIV status and access to selftesting remains low This situation could change quickly, however, considering that an HIV-self test is already sold legally in the UK [8] and France [9]. Some Spanish MSM may well decide to purchase and use the legal and reliable commercial kits sold in these two countries, considering the fluid interconnections among gay communities in these countries and the absence of borders for goods and merchandise. In countries where self-testing is yet to be authorized, there may also be an increase in the unregulated trade of illegal kits with similar presentations to those approved in the aforementioned countries. Nevertheless, these tests will not necessarily comply with the handling, storing and distribution conditions of legally purchased tests. Furthermore, they will not offer any kind of telephone or web support for interpretation of results, counselling, referral or linkage to services for care and support. Moreover, other presentations with fewer, if any, guarantees, will continue to be sold online and probably at a lower cost. All these considerations should be taken into account when evaluating the advantages and drawbacks of regulating these tests in EU member countries.

\section{Abbreviations}

CBO, community based organization; $\mathrm{CI}$, confidence interval; FDA, United States Food and Drug Administration; LGTB, lesbian gay transexual and bisexual; MSM, men who has sex with men; NGO, nongovernmental organization; OR, odds ratio; STI, sexually transmitted infections; UK, United Kingdom

\section{Additional file}

Additional file 1: Contains the data used in the analysis. (XLSX $9721 \mathrm{~kb}$ )

\section{Acknowledgements}

We would like to thank the contributions made by Ignacio Alonso-López Iciar Indave, Ana Sarasa and Fernando Vallejo.

\section{Funding}

This study was supported by the Spanish Ministerio de Sanidad, Servicios Sociales e Igualdad (MSSSI EC11-279) and the Consumers, Health and Food Executive Agency (20131101)

Availability of data and materials

Additional data file1.xls contains all the data used in the analysis.

\section{Authors' contributions}

$M B$ and LF were responsible of the conception and design of the study. KK, MERS, JH, CA, SFB were in charge of the analysis and interpretation of data and MR of the data collection process. All authors were involved in the drafting of the manuscript and critically reviewed it for important intellectual content. All authors gave their approval on the final version to be published and agreed to be accountable for all aspects of the work.

\section{Competing interests}

The authors declare that they have no competing interests.

Consent for publication

Not applicable.

Ethics approval and consent to participate

The study was approved by the Carlos III health institute ethical committee (CEI PI 70_2015). Candidates were asked to click on an "I agree to participate button" before having access to the questionnaire

\section{Author details}

${ }^{1}$ European Programme for Intervention Epidemiology Training (EPIET), European Centre for Disease Prevention and Control (ECDC), Stockholm, Sweden. ${ }^{2}$ National Epidemiology Centre, Carlos III Health Institute, Madrid, Spain. ${ }^{3}$ Consortium for Biomedical Research in Epidemiology \& Public Health (CIBERESP), Madrid, Spain. ${ }^{4}$ National School of Health, Carlos III Health Institute, Madrid, Spain. ${ }^{5}$ Centre for Epidemiological Studies on STI/HIV/AIDS in Catalonia (CEEISCAT)-ICO-Agència de Salut Pública de Catalunya, Barcelona, Spain.

Received: 29 January 2016 Accepted: 17 June 2016

Published online: 08 July 2016

References

1. National AIDS Trust. Home Testing for HIV. A position paper by NAT on home sampling and self-testing for HIV in the UK. London: National AIDS Trust; 2008.

2. Owens SL, Arora N, Quinn N, Peeling RW, Holmes KK, Gaydos CA. Utilising the internet to test for sexually transmitted infections: results of a survey and accuracy testing. Sex Transm Infect. 2010;86(2):112-6.

3. Roehr B. FDA approves "instant" HIV home test. BMJ. 2012;345, e4636. 
4. Epstein J. July 3, 2012 Approval Letter, Oraquick In-Home HIV Test. U.S. Food and Drug Administration.U.S. Department of Health and Human Services; 2013. http://www.fda.gov/BiologicsBloodVaccines/BloodBloodProducts/ ApprovedProducts/PremarketApprovalsPMAs/ucm310592.htm. Accessed 6 Jul 2016.

5. Myers JE, El-Sadr WM, Zerbe A, Branson BM. Rapid HIV self-testing: long in coming but opportunities beckon. AIDS. 2013;27(11):1687-95.

6. UK Parliament. Early day motion 426: HIV Self-testing. UK Parliament; 2013. http://www.parliament.uk/edm/2012-13/5515/pamela-nash. Accessed 6 Jul 2016.

7. Ministere des Affaires sociales et de la Santé. Dépistage du VIH: poursuite de la procédure d'évaluation de la mise a disposition d'autotests. Ministere des Affaires sociales et de la Santé; 2013. http://social-sante.gouv.fr/ actualites/presse/communiques-de-presse/annee-2013/article/depistage-duvih-poursuite-de-la-procedure-d-evaluation-de-la-mise-a. Accessed 6 Jul 2016.

8. Biosure. Biosure HIV self test; 2015. http://hivselftest.co.uk/. Accessed 6 Jul 2016.

9. Sida: les autotests de déspistage désomais en vente en pharmacie. http:// www.lemonde.fr/sante/article/2015/09/14/sida-les-autotests-de-depistagebientot-en-vente-en-pharmacie_4756942_1651302.html. Accessed 6 Jul 2016.

10. Belza MJ, Figueroa C, Rosales-Statkus ME, Ruiz M, Vallejo F, de la Fuente L. Low knowledge and anecdotal use of unauthorized online HIV self-test kits among attendees at a street-based HIV rapid testing programme in Spain. Int J Infect Dis. 2014;25:196-200.

11. Bavinton BR, Brown G, Hurley M, Bradley J, Keen P, Conway DP, et al. Which gay men would increase their frequency of HIV testing with home selftesting? AIDS Behav. 2013;17(6):2084-92.

12. Napierala MS, Baggaley R, Corbett EL. A review of self-testing for HIV: research and policy priorities in a new era of HIV prevention. Clin Infect Dis. 2013;57(1):126-38.

13. King G, Zeng L. Logistic regression in rare events data. Polit Anal. 2001;9: 137-63.

14. Tomz M, King G, Zeng L. Rare Events Logistic Regression, Version 1.1. Cambridge, MA: Harvard University; 1999.

15. Greacen T, Friboulet D, Fugon L, Hefez S, Lorente N, Spire B. Access to and use of unauthorised online HIV self-tests by internet-using French-speaking men who have sex with men. Sex Transm Infect. 2012;88(5):368-74

16. Figueroa C, Johnson C, Verster A, Baggaley R. Attitudes and acceptability on hiv self-testing among key populations: a literature review. AIDS Behav. 2015:19(11):1949-65.

\section{Submit your next manuscript to BioMed Central and we will help you at every step:}

- We accept pre-submission inquiries

- Our selector tool helps you to find the most relevant journal

- We provide round the clock customer support

- Convenient online submission

- Thorough peer review

- Inclusion in PubMed and all major indexing services

- Maximum visibility for your research

Submit your manuscript at www.biomedcentral.com/submit 